Military Technical College

Kobry El-Kobbah,

Cairo, Egypt

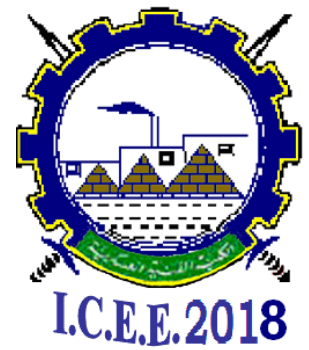

EPC-4 $9^{\text {th }}$ International Conference on

Chemical \& Environmental

Engineering

3-5 April 2018

\title{
Supports Delivering Sustainable Environment Using Drinking Water Treatment Plant Waste for Sullage Treatment: Box- Behnken Design Model for Process Optimization
}

\author{
Maha A. Tony
}

\begin{abstract}
:
Currently, a great attention has drawn by the academic world and industry to safe the environment. In Egypt, large amounts of by product waste, namely alum sludge (AS), is generated from the drinking water treatment (DWT) plant that must be discarded. A recent trend in such sludge management is transferring it to a valuable resource which is critically provides the environmental protection and sustainable development. On the other hand, sullage (graywater) wastewater is produced as a domestic wastewater that does not contain the toilet effluent. A crucial issue is to find a low-cost adsorbent for treating this waste for its final disposal or reuse. This study investigates the opportunity of integrating water treatment plant sludge waste into an adsorbent material. The main goal is converting sullage for non-potable purpose focusing on alum sludge adsorbent that is simple and economical adsorbent. Primarily, the collected alum sludge is dewatered and prepared as an adsorbent material. Moreover, the wastewater is subjected to the adsorption process after the sullage is exposed to a physical pre-treatment. A response surface methodology involving an experimental design was used to optimize the effects of sample stirring, pollutant load and adsorbent dosage on sullage waste treatment and obtained the optimum value of the three process variables. The adequacy of the model was verified effectively by the validation of experimental data. Additionally, the optimum results show that the sullage treatment is reached to $60 \%$ removal after $2 \mathrm{~h}$ of reaction time. The results presented that the drinking water plant sludge could be used in sullage treatment, helping in reducing both the impacts of water treatment plants and domestic sullage for further usage.
\end{abstract}

\section{Keywords:}

Launderette wastewater, alum sludge, adsorption, RSM, optimization

Faculty of Engineering, Menoufia University, Shebin El-Kom, Egypt

E-mail: dr.maha.tony@gmail.com 

Military Technical College
Kobry El-Kobbah, Cairo, Egypt

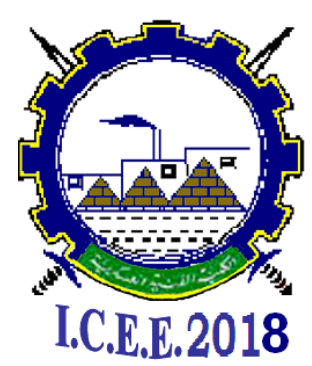

$9^{\text {th }}$ International Conference on

Chemical \& Environmental

Engineering

3-5 April 2018

\section{Introduction:}

Due to urbanization, sullage is in increase day by day. Sullage or so-called graywater refers to the water disposed from sinks, showers, baths, laundry washing, food, dishes washing and kitchen utilities, however, does not includes the sewage or toilets water. Thus, sullage includes low loads of organic substances and nutrients than black water [1, 2]. Moreover, low loads wastewaters contain low concentration of detergent. Some of those detergents are in quite high loads of phosphates; consequently the detergent is a source of aquatic environmental deterioration. Until now, although restrict environmental regulations and laws on using this types of detergent, no impact dismissing the aquatic deterioration. Thus, efforts began to control this type of wastewater disposed to the aquatic environment [3]. Furthermore, treatment of sullage is also considered be a potential source of water that decreasing the demand on potable water supplies. Thus, recently, in the last years there is a great attention has been paid to reach to an economic way to treat wastewater [4].

Generally, there is a reasonable strong affinity for phosphate ion to mineral surface [5]. Hence, researchers focused on investigation of low cost adsorbents as fly ash and slag [6], red mud [7], goethite [8] and alum sludge [9, 10] in treating water containing phosphate.

Alum sludge (AS) that is referring to the waste by-product which is in rich of aluminum hydroxide; produced from the drinking water treatment (DWT) plant as a result of using aluminum sulphate as a coagulant aid. In Egypt, alum sludge is disposed of without treatment to the natural waterway, i.e. River Nile or to the nearest site to the plant. Hence, such sludge contains high loads of aluminium which is toxic to the aquatic life $[11,12]$. However, the dewatered alum sludge is rich with the amorphous aluminium ions makes it a valuable adsorbent for pollutant removal $[13,14]$.

This manuscript builds on our previous work [15-19], which dealt with the conditioning and dewatering of alum sludge using different techniques. The current trend of sludge management is to convert the dewatered sludge into useful materials.

Although a special concern has been gone to the management of alum sludge in recent years $[9,10,16,20]$, as an adsorbent, its use remains in an early stage. However, according to the literature, there is a lack in publications in using alum sludge as adsorbent material for sullage wastewater.

The response surface methodology (RSM) is a assembly of mathematical and statistical methods for designing experiments, estimating the effects of factors and searching optimum condition of factors for desirable responses [21]. The optimisation process of this methodology involves examining the response of the statistically designed variables, approximating the parameters by fitting it in a mathematical model that installs best the 
Military Technical College

Kobry El-Kobbah, Cairo, Egypt

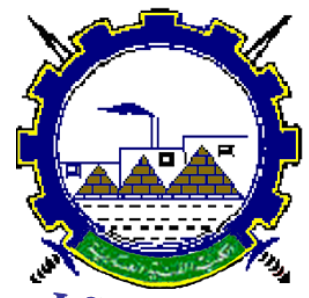

I.C.E.E.2018 $9^{\text {th }}$ International Conference on

Chemical \& Environmental

Engineering

3-5 April 2018

experimental settings. Subsequently, predicting the response of the fitted model and examining the suitability of the model. Box-Behnken design [20,22] is one of the most common designs for the principal of response surface methodology and applied in various experiments for optimization of its variables [15, 23, 24].

The global target of this study is to evaluate and optimize the effectiveness and capacity of low-cost adsorbent, alum sludge, for treating such sullage.

\section{Materials and Methods:}

\subsection{Materials}

Alum sludge is collected from the field site in Menoufia governorate in Shebin El-Kowm city, Egypt, treatment plant $(400 \mathrm{~L} / \mathrm{sec})$. The sludge is dewatered and dried in a dry furnace at $105^{\circ} \mathrm{C}$ for 24 hours, then the dried sludge cake is sieved for different particle sizes. The complete chemical composition of (WDAS) sludge is summarized in Table 1. Sullage effluent used in this present work as the wastewater source was collected from a commercial laundry facility in the city of Shebin El-Kowm, Egypt. This laundry system is operated with a standard washing machine programme using a powder detergent. The sullage water obtained from the first wash cycle and from the final rinsing cycle with different COD loads. Samples were collected and analyzed before treatment. The main characteristics of this wastewater are $\mathrm{pH} 7.2$, suspended solids 31-66 mg/L, COD (84-700 $\mathrm{mg} / \mathrm{L})$.

\subsection{Methodology}

Initially, eequilibrium uptake was investigated according to the preliminary work. The solution with the sludge was mechanically shaken for 2 hours. Thereafter, the samples were centrifuged at $400 \mathrm{rpm}$ for 15 minutes to separate the sorbent material. Subsequently, the equilibrium concentration of the Chemical Oxygen Demand (COD) remaining in solution was determined using the standard methods [25]. The saturated isotherm can be represented as a linear form:

$$
q_{e}=0.025\left(C_{o}-C_{e}\right)(m / V)
$$

Where $\mathrm{Co}$ and $\mathrm{Ce}$ is the initial and the equilibrium concentration of the sullage COD load $(\mathrm{mg} / \mathrm{L})$, respectively, qe is the equilibrium COD load on the adsorbent $(\mathrm{mg} / \mathrm{g}), \mathrm{V}$ is the volume of aqueous solution (L), and $\mathrm{m}$ is the mass of dewatered DWT-AS sample used (g). The process steps are illustrated in Fig. 1. 
Military Technical College Kobry El-Kobbah, Cairo, Egypt

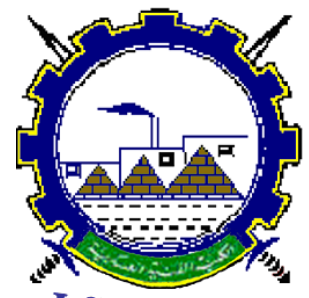

I.C.E.E.2018 $9^{\text {th }}$ International Conference on

Chemical \& Environmental

Engineering

3-5 April 2018

\subsection{Experimental Design}

Box-Behnken design with a 15 run is used as RSM tool that contains a three variables, namely, COD load of the wastewater, dewatered DWT-AS dose and sample-stirring rate. Ranges and levels of the natural and the corresponding coded values are presented in Table 2.

The second-order polynomial equation model [26] to predict the optimum value of three factors can be stated according to Eq. (2):

$$
\gamma=\beta_{o}+\sum \beta_{i} X_{i}+\sum \beta_{i i} X_{i}^{2}+\sum \sum \beta_{i j} X_{i} X_{j}
$$

Where $\gamma$ is the predicted response (COD removal rate, \%) used as a dependent variable, $\mathrm{i}$ $=1,2,3$ and $\mathrm{j}=1,2,3 ; \beta_{0}, \beta_{\mathrm{i}}, \beta_{\mathrm{ii}}$ and $\beta_{\mathrm{ij}}$ are the model regression coefficient parameters; and $\mathrm{Xi}$ is the input controlling coded variable. In addition, the natural variables of the operating system $\left(x_{\mathrm{i}}\right)$ were transferred to coded variables. Statistical Analysis System (SAS) [27] was used for analysis of variances (ANOVA). Three 3-D plots surface and contour plots (using MATLAB 7.0 software) were attained based on the effects of the levels of the three variables. Ultimately, the accurate optimum operating parameters were located using Mathematica software (V 5.2).

\section{Results and Discussion}

\subsection{Mathematical Model building}

A 15-run Box-Behnken design with three factors and three levels, including three replicates at the centre point, was used for fitting a second-order response surface. The three centre point runs were added to provide as a measure of maximum adsorption capacities $\left(\mathrm{q}_{\max }\right)$ yield. The detailed experimental design includes the considerable variation in the process conditions was shown in Table 3.

As can be seen from Table 4 the application of dewatered alum sludge had a positive effect in COD removal under all conditions evaluated, leading to a significant increase in the sullage treatment. Values in Table 3 were adjusted to a second-order polynomial expression including interactions as presented in Equation 3.

$$
\begin{aligned}
f & =55.19+1.23 X_{1}+1.66 X_{2}+11.54 X_{3}-10.33 X_{1}^{2}-0.3 X_{1} X_{2} \\
& +0.53 X_{1} X_{3}-2.53 X_{2}^{2}+0.21 X_{2} X_{3}-8.02 X_{3}^{2}
\end{aligned}
$$



Military Technical College
Kobry El-Kobbah, Cairo, Egypt

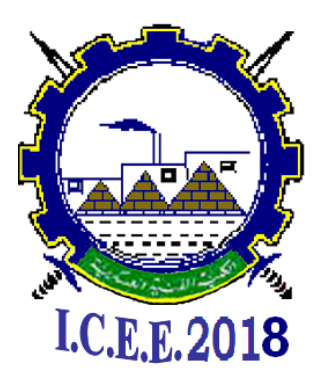

$9^{\text {th }}$ International Conference on

Chemical \& Environmental Engineering

3-5 April 2018

Where $f$ is the \% of the COD removal by alum sludge; $X_{1}, X_{2}$ and $X_{3}$ are the coded values of the operational variables COD load, adsorbent concentration and sample-stirring, respectively. The $R^{2}$ value provides a measure of how much variability in the observed response values can be explained by the experimental factors and their interactions. The value is always between 0 and 1 . The closer the $R^{2}$ value is to 1.00 , the stronger the model is and the better it predicts the response. When expressed as a percentage, $R^{2}$ is interpreted as the percent variability in the response explained by the statistical model. This ensured a satisfactory adjustment of the quadratic model to the experimental data. The comparison between the experimental and predicted data is given in Fig. 2.

\subsection{Model fitting and statistical analysis}

Statistical parameters obtained from the analysis of variance (ANOVA) incorporating the lack-of-fit test for the reduced model of the pollutant removal is given in Table 4. The analysis was done by means of the coefficient of correlation $\left(R^{2}\right)$ of the experimental data and by means of Fisher's $(F)$ test. The correlation coefficient is a measure of the goodness of fit between the model and experimental data. The $F$ test is used to determine the significance of the regression coefficients of the parameters. The analysis of variance table is composed of the following columns: Source (the source of the variation); DF (the degree of freedom); SS (the sums of squares); MS (the mean squares); Fisher F values; Probability $\mathrm{P}$ values. The sum of the squares (SS) is the summation of the squares of the dependent variables. The mean squares (MS) column lists the mean squares, which are the sums of squares, divided by the degree of freedom. The $\mathrm{F}$ value is defined as follows:

$$
\mathrm{F} \text { value }=\frac{\text { Between groups } \text { var iance }}{\text { Pooled } \text { variance }}
$$

In general, the larger the magnitude of the $F$ and the smaller the value of $P$ (the probability of exceedance of $F$ ) the more significant is the corresponding coefficient term. The model is significant when the $P$-value is less than $0.05[26,27]$. Since $R^{2}$ always decreases when a regressor variable is dropped from a regression model, in statistical modeling the adjusted $R^{2}$, which takes the number of regressor variables into account, is usually selected [27]. Based on the lack-of-fit analysis, the second-order response model appeared to adequately fit the data. The $R^{2}$ coefficient gives the proportion of the total variation in the response variable explained or accounted for by the predictors (X's) included in the model. In the present study, the adjusted $R^{2}$ ranged from 96.36 (for MB colour removal) which mean the satisfactory adjustment of the model to the experimental data. The P-values were used as a tool to check the significance and this model explains about $98.7 \%$ of the data variability. The measured and the predicted data 
Military Technical College Kobry El-Kobbah, Cairo, Egypt

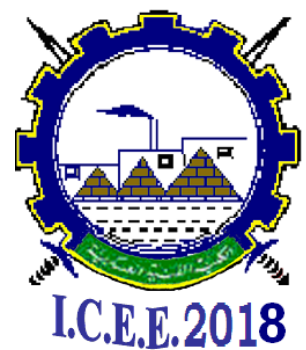

$9^{\text {th }}$ International Conference on

Chemical \& Environmental Engineering

3-5 April 2018

obtained by Eq. (2) are shown in Fig. 2. It shows that the proposed empirical model is suitable for predicting COD removal, revealing a reasonably good agreement.

\subsection{Response surface plotting}

In order to gain a better understanding of the results, the graphical interpretation of the interactions of the predicted model is presented in Fig. 3 (a, b, c). The three-dimensional response surface plots of the regression model are highly recommended. By fixing one parameter at its zero level, it was possible to graphically represent the relationship between the percentage colour removal and the other two independent variables using MATLAB 7.0. RSM optimization tests confirm that alum sludge adsorption process could enhance the COD removal in sullage capacity under the optimum conditions.

\subsection{Validation of the model}

One of the primary objectives of the present study was to find the optimum process parameters for maximizing the adsorption process. In order to verify of the model developed, 3 more experiments were performed to verify the optimum process parameters (Table 5) for maximizing the adsorption process. Under these conditions, the predicted adsorption capacity was $60 \%$ which was in good agreement with the experimental value of $61 \%$, which thus proves the validity.

\section{Conclusion}

In this study, response surface methodology involving an experimental design was used to optimize the sullage treatment. The adequacy of the model was verified effectively by the validation of experimental data. Additionally, the optimum results show that the COD removal reached to $60 \%$. A further advantage in the usage of alum sludge includes as safe and environmental friendly adsorbent. It could replace the conventional chemical adsorbent. Additionally, it is considered as a valuable usage of the waste alum sludge byproduct. As a conclusion, the application of alum sludge technique was successfully applied in the sullage wastewater treatment. This technique could be extended for other research activities. 
Military Technical College

Kobry El-Kobbah, Cairo, Egypt

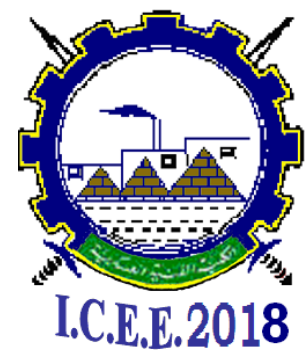

$9^{\text {th }}$ International Conference on

Chemical \& Environmental

Engineering

3-5 April 2018

\section{References}

[1] E. Friedler, R. Kovalio and N. Galil, On-site greywater treatment and reuse in multi storey buildings, Water Sci. Technol. 51 (10) (2005) 187-194.

[2] R.Saranya and S.Shanmugapriya, R.Subashini, Experimental Study On Treatment Of Sullage Waste Water Using Coagulants, SSRG Inter. J. Civil Eng. (ICRTCETM2017) Special Issue - April (2017) 76-80.

[3] S. Sostar-Turk, I. Petrinic and M. Simonic, Laundry wastewater treatment using coagulation and mem- brane filtration, Resou., Conser. Recyc., 44 (2005) 185-196.

[4] I. Ciabattia, F. Cesarob, L. Farallia, E. Fatarellaa and F. Tognotti, Demonstration of a treatment system for purification and reuse of laundry wastewater, Desal. 245 (2009) 451-459.

[5] W. Stumm, Chemistry of the solid-water interface. Processes at the mineral-water and particle-water interface in natural systems, Wiley, NY, 1992.

[6] N. Agyei,C.A.Strydom and J.H.Potgieter,Aninvestigation of phosphate ion adsorption from aqueous solution by fly ash and slag, Cem. Concr. Res. 30 (2000) 823-826.

[7] J. Pradhan, J. Das, S. N. Das and R. Thakur, Adsorption of phosphate from aqueous solution using activated red mud, J. Colloid Interface Sci. 204 (1998) 169-172.

[8] D. Buerge-Weirich, R. Hari, H. Xue, P. Behra and L. Sigg, Adsorption of Cu, Cd and $\mathrm{Ni}$ on goethite in the presence of natural groundwater ligands, Environ. Sci. Technol. 36 (2002) 328-336.

[9] E. Galarneau and R. Gehr, Phosphorus removal from wastewaters: experimental and theoretical support for alternative mechanisms, Water Res. 31 (1997) 328-338.

[10] A. Babatunde and Y.Q. Zhao, Equilibrium and kinetic analysis of phosphorus adsorption from aqueous solution using waste alum sludge, J. Hazard. Mater. 184 (13) (2010) 746-752.

[11] A. Elawwad, E. Rashed and M. Sadawy, Re-use of water treatment sludge (Alum sludge) in enhancement of domestic wastewater treatment processes, J. Al Azhar Uni. Eng. Sector, 4 (11) (2009) 261-272.

[12] Sh.A.Rizk, A.A. Mageed, M.H. Abu-Ali, dewatering the sludge generated from water treatment plants with two hydrocyclones in series, J. Eng. Sci., 38(3), (2010) 797-806.

[13] S.H. Huang, and B. Chiswell, Phosphate removal from wastewater using spent alum sludge. Water Sci. \& Technol., 42(3-4) (2000) 295-300.

[14] W. Chu, Dye removal from textile dye wastewater using recycled alum sludge. Wat. Res., 35(13) (2001) 3147-3152.

[15] M.A. Tony Y.Q. Zhao, J.F. Fu and A.M. Tayeb, Conditioning of aluminium-based 
Military Technical College

Kobry El-Kobbah, Cairo, Egypt

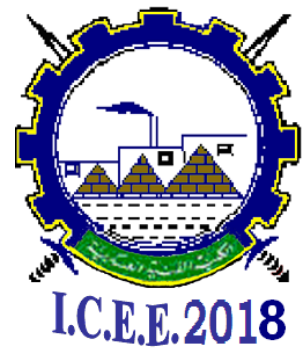

$9^{\text {th }}$ International Conference on

Chemical \& Environmental Engineering

3-5 April 2018

water treatment sludge with Fenton's reagent: Effectiveness and optimising study to improve dewaterability. Chemosphere, 72 (2008) 673-677.

[16] M.A. Tony Y.Q. Zhao, and A.M. Tayeb, Exploitation of Fenton and Fenton-like reagents as alternative conditioners for alum sludge conditioning, Journal of Environmental Sciences, Vol. 20(1) (2009) 101-105.

[17] M.A. Tony Y.Q. Zhao, and M.F. El-Sherbiny, Fenton and Fenton-like AOPs for alum sludge conditioning: Effectiveness comparison with different $\mathrm{Fe} 2+$ and $\mathrm{Fe} 3+$ salts, Chemical Engineering Communications, 198 (3) (2011) 442- 452.

[18] M.A. Tony, A.M. Tayeb, and Y.Q. Zhao, An alternative arrangement for the alum sludge management: Minimising waste with low-cost solar techniques, Amer. J. Chem. Eng. 4(2) (2016) 30-37.

[19] M.A. Tony and A.M. Tayeb,, Response surface regression model in optimization of alum sludge drying facility: solar-Fenton's reagent dewatering, Inter. J. Chem. Eng. Applications, 7(5) (2016) 331-335.

[20] P. Lara, J. Rodriguesa and F. Holanda, Recycling of Water Treatment Plant Waste for Production of Soil- Cement Bricks, International Congress of Science and Technology of Metallurgy and Materials, SAM - CONAMET 2013.

[21] G. Box, W. Hunter and J. Hunter, Statistics for Experimenters. (John Wiley \& Sons, Inc), pp. 510-539, 1978.

[22] A. Dean and D. Voss, Design and Analysis of Experiments. Springer-Verlag, Inc, NY. 547-558,1999.

[23] S. Oscar, S. Gerardo, L. Jose, G. Mariano, G.R. and F. Ernesto, Effect of substrate composition on the mycelial growth of Pleurotus ostreatus: an analysis by mixture and response surface methodologies, Process Biochemistry, 35 (1999) 127-133.

[24] G. Muthuraman and K. Palanivelu, Transport of textile dye in vegetable oils based supported liquid membrane, Dyes Pig. 70 (2006) 99-104.

[25] APHA-AWWA-WEF, Standard methods for the examination of water and wastewater.20th edn. American Public Health Association, Washington, DC., 1998.

[26] Montgomery, D. C., Design and Analysis of Experiments, John Wiley\&Sons, New York, USA, 1991.

[27] SAS, SAS /STAT User's Guide, SAS Institute, Inc., Cary, NC, 1990. 


\begin{tabular}{|c|c|}
\hline Proceeding of the $9^{\text {th }}$ ICEE Conference 3-5 April 2018 & EPC \\
Military Technical College \\
Kobry El-Kobbah, \\
Cairo, Egypt
\end{tabular}

Table 1 Chemical Composition of dewatered DWT- AS

\begin{tabular}{ll}
\hline Ingredient & Ratio by weight $(\%)$ \\
\hline $\mathrm{SiO}_{2}$ & 46.17 \\
$\mathrm{Al}_{2} \mathrm{O}_{3}$ & 17.33 \\
$\mathrm{Fe}_{2} \mathrm{O}_{3}$ & 4.86 \\
$\mathrm{Mn}_{2} \mathrm{O}_{3}$ & 0.29 \\
$\mathrm{MgO}$ & 2.14 \\
$\mathrm{SO}$ & 0.18 \\
$\mathrm{CaO}$ & 13.5 \\
$\mathrm{Cl}$ & 0.10 \\
L.O.I. & 15.43 \\
\hline
\end{tabular}

Table 2 Range and levels of natural and corresponded coded variables for RSM

\begin{tabular}{cccccccc}
\hline \multirow{2}{*}{ Variable } & \multicolumn{2}{c}{ Symbols } & & \multicolumn{3}{c}{ Range and levels } \\
\cline { 2 - 3 } \cline { 6 - 8 } & Natural & Coded & & -1 & 0 & 1 \\
\hline Sample stirring (rpm) & $x_{1}$ & $X_{1}$ & & 400 & 600 & 800 \\
COD concentration & $x_{2}$ & $X_{2}$ & & 100 & 400 & 700 \\
(mg/l) & $x_{3}$ & $X_{3}$ & & 1.0 & 2.0 & 3.0 \\
\hline
\end{tabular}




\begin{tabular}{|c|c|}
\hline Proceeding of the $9^{\text {th }}$ ICEE Conference 3-5 April 2018 & EPC \\
Military Technical College \\
Kobry El-Kobbah, \\
Cairo, Egypt
\end{tabular}

Table 3 Experimental factors in coded units and experimental response

\begin{tabular}{ccccc}
\hline \multirow{2}{*}{ Run no. } & \multicolumn{3}{c}{ Coded factors } & \multirow{2}{*}{ Experimental Response $(f)$} \\
\cline { 2 - 4 } & $X_{1}$ & $X_{2}$ & $X_{3}$ & 38.275 \\
2 & -1 & -1 & 0 & 43.340 \\
3 & -1 & 1 & 0 & 41.913 \\
4 & 1 & -1 & 0 & 45.764 \\
5 & 1 & 1 & 0 & 30.582 \\
6 & 0 & -1 & -1 & 56.326 \\
7 & 0 & -1 & 1 & 32.351 \\
8 & 0 & 1 & -1 & 58.932 \\
9 & 0 & 1 & 1 & 26.324 \\
10 & -1 & 0 & -1 & 27.152 \\
11 & 1 & 0 & -1 & 45.276 \\
12 & -1 & 0 & 1 & 48.213 \\
13 & 1 & 0 & 1 & 55.560 \\
14 & 0 & 0 & 0 & 55.000 \\
15 & 0 & 0 & 0 & 55.000 \\
\hline
\end{tabular}

Table 4 Analysis of Variance (ANOVA) for the RSM Model

\begin{tabular}{llllll}
\hline Source & $\begin{array}{l}\text { Degree of freedom } \\
(\mathrm{df})\end{array}$ & $\begin{array}{l}\text { Sum of squares } \\
(\mathrm{SS})\end{array}$ & $\begin{array}{l}\text { Mean squares } \\
(\mathrm{MS})\end{array}$ & $\begin{array}{l}\text { Fisher } \\
\text { F- } \\
\text { values }\end{array}$ & $\begin{array}{l}\text { Probability } \\
\text { p-values }\end{array}$ \\
\hline Model & 9 & 1700.22 & 188.910 & 42.179 & 0.0003 \\
Linear & 3 & 1099.94 & 1099.93 & 245.58 & 0.2387 \\
Square & 3 & 660.870 & 660.868 & 147.55 & 0.0710 \\
Interaction & 3 & 0.65550 & 1.65555 & 0.3693 & 2.2761 \\
Error & 5 & 22.3943 & 4.47887 & & \\
Total & 14 & 1722.60 & & &
\end{tabular}


Military Technical College

Kobry El-Kobbah,

Cairo, Egypt

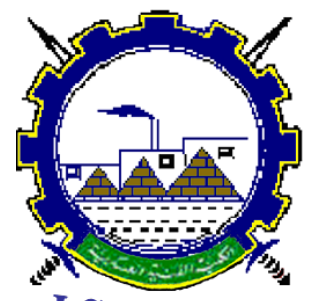

I.C.E.E.2018 $9^{\text {th }}$ International Conference on

Chemical \& Environmental

Engineering

3-5 April 2018

Table 5 Optimum value of the process parameter for maximum efficiency

\begin{tabular}{cc}
\hline Parameters & Optimum values \\
\hline$q_{\max }$ & $60 \%$ \\
Sample stirring $(\mathrm{rpm})$ & $614 \mathrm{rpm}$ \\
COD load $(\mathrm{mg} / \mathrm{l})$ & $427 \mathrm{mg} / \mathrm{L}$ \\
DWT-AS mass $(\mathrm{mg} / \mathrm{l})$ & $2.6 \mathrm{mg} / \mathrm{L}$ \\
\hline
\end{tabular}

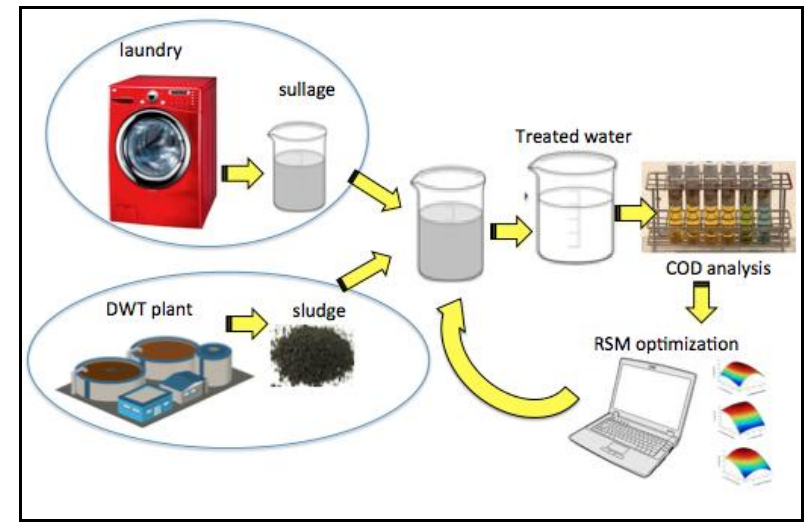

Fig. 1 Schematic representation for the experimental set-up

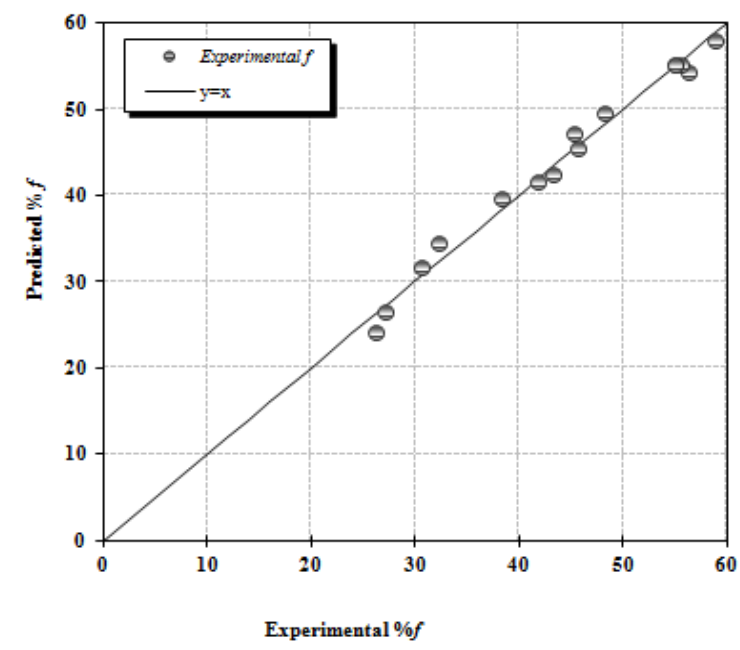

Fig. 2 Comparison between the experimental values and the predicted values of model 
Military Technical College Kobry El-Kobbah, Cairo, Egypt

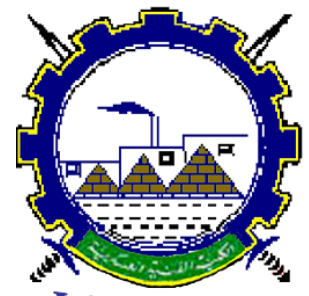

I.C.E.E.2018 $9^{\text {th }}$ International Conference on

Chemical \& Environmental

Engineering

3-5 April 2018 (a)

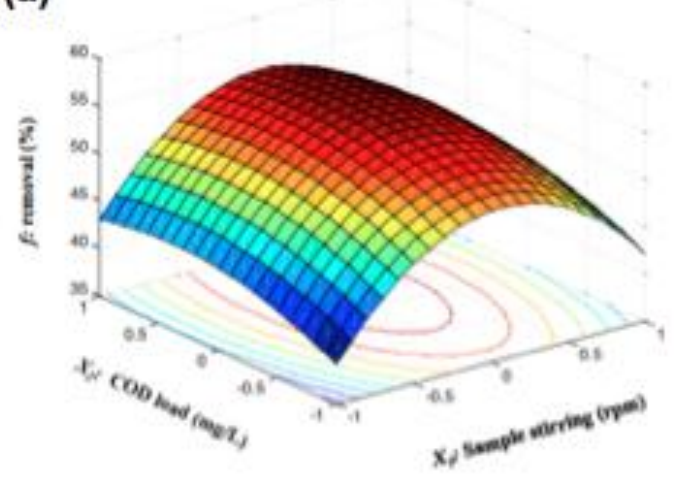

(b)

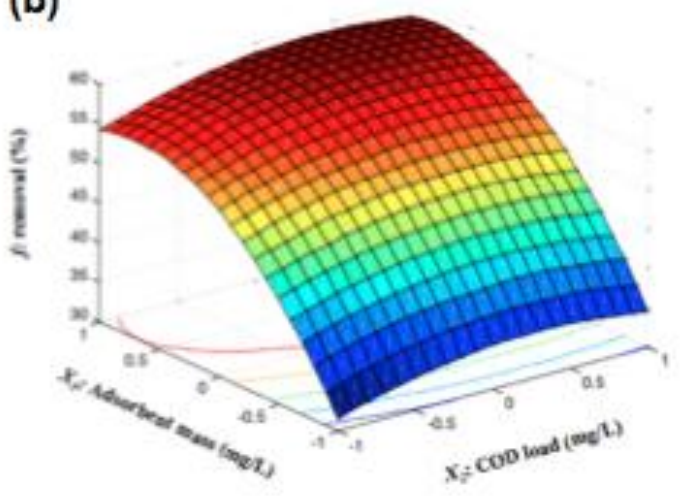

(c)

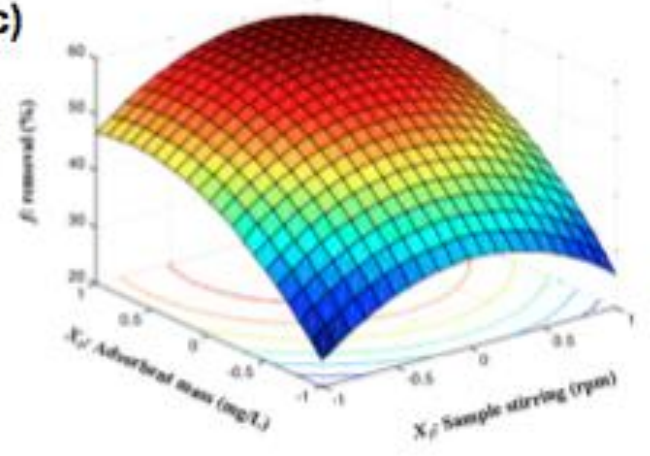

Fig. 2 3D- Response surface and contour plot of COD removal (\%) for the three operating variables 